which returns them to regions of the photographic emulsion corresponding to masses higher than those of the main isotopes.

If, however, ions lose their charges more rapidly during passage through the emulsion, fewer of them are reflected. Swift ${ }^{2}$ confirmed this view experimentally.

$\mathrm{Mai}^{3}$ has shown that if the photographic plate is cut into parts in such a way that the ions of the main component do not strike the emulsion at all, no halo is produced.

All these precautions are fairly complicated. An easy and simple method of eliminating halation consists of painting a small conducting strip on the spot at which the main isotope line(s) will appear. This can easily be done in the dark room before the plate is placed in its hold using a rule and a small brush. This painted strip can be earthed by applying a second strip at the bottom of the plate so as to make contact with one of the pins on which the plate rests. If the strip is not earthed the effect is very poor.

The paint consists of a mixture of $300 \mathrm{mg}$ graphite powder, $100 \mathrm{mg}$ cellulose nitrate and polyvinyl acetate, and $180 \mathrm{mg}$ ethyl acetate. After drying, the layer has a thickness of about $0.1 \mathrm{~mm}$. Graphite has been chosen because of its low mass, which gives greater depth of penetration ${ }^{4}$ and more chance of the ions losing their charge.

Figs. I $A$ and $B$ show Joyce Loebl densitometer recordings without and with the use of the strip of graphite paint mentioned above. This strip has a width of $4 \mathrm{~mm}$ on the plate. The mass spectrogram (obtained with an A.E.I. $M . S .7$ instrument) is of gallium with arsenic present as an impurity.

This work was carried out with the assistance of Miss H. Savenije, Mr. H. Kraay and Mr. A. Witmer.

Philips Research Laboratories,

$$
\text { N. W. H. ADDINK. }
$$

N.V. Philips' Gloeilampenfabrieken,

Eindhoven, The Netherlands.

${ }^{1}$ Addink, N. W. H., Limitations of Detection in Spectrochemical Analysis, 106 (Hilger and Watts Ltd., London, 1964).

2 Swift, P., Proc. Fifth Ann. A.E.I.-M.S.7 Users' Meeting, 12 (1965).

${ }^{3}$ Mai, H., Adv. Mass Spectrom., 3, 163, edit. by Mead, W. L. (Elsevier Amsterdam, 1966). Proc. Fifth Ann. A.E.I.M.S.7 Users' Meeting, 60 (1965). 4 Mass Spectrometry, edit. by Reed, R. I., 225 (Academic Press, London and
New York, 1965).

\section{THE SOLID STATE}

\section{Fast Domain Wall Motion in Double Nickel-Iron Films}

RECENTLY, Humphrey and Clow ${ }^{1}$ found that flux reversal in multilayer films ${ }^{2}$, consisting of $200 \AA$ thick nickel-iron films interleaved with silicon monoxide layers each about 100 A thick, was much faster than that observed in normal single films. A possible explanation for this fast flux reversal might be that domain wall motion is much faster in multilayer than in single films. To verify this assumption, Patton and Humphre ${ }^{3}$ have measured wall velocities in double films. For small driving fields, the wall velocity obeys the relation

$$
V=m\left(H-H_{c}\right)
$$

in which $H$ is the applied field, $H_{c}$ the wall motion coercive force and $m$ the so-called wall mobility. Patton and Humphrey found that-contrary to expectation-the wall mobilities in double and in single films were about the same.

This communication reports the results of wall velocity measurements in double nickel-iron films (81/19) which show that wall mobilities in double films are much larger than those measured in singlo nickel-iron films. The measuring technique used has already been described ${ }^{4}$ and is similar to that used by Patton and Humphrey ${ }^{3}$.

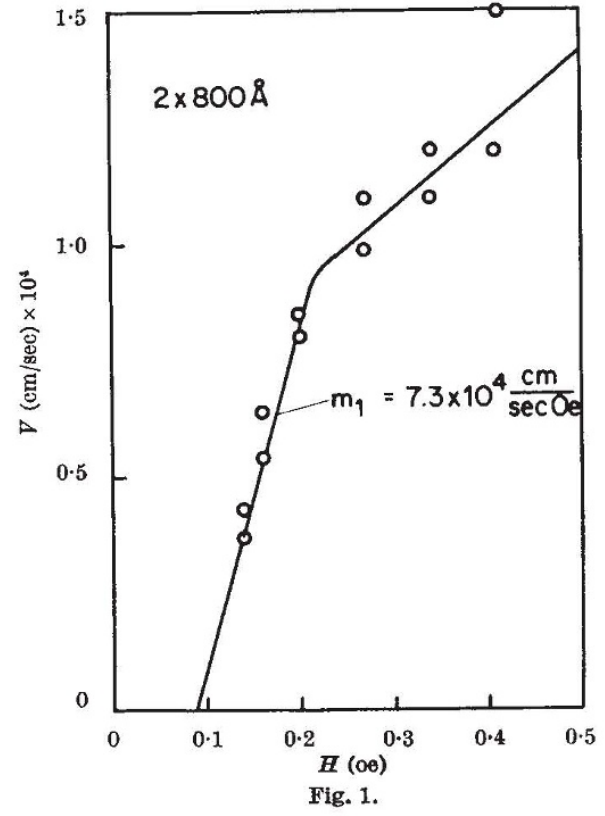

Fig. I shows the wall velocity measured in a double film $\left(2 \times 800 \AA\right.$ nickel-iron, $100 \AA \mathrm{SiO}, H_{c}=0.09 \mathrm{oe}$, $H_{k}=\mathbf{5 . 4} \mathrm{oe}$ ) as a function of the applied field. The wall mobility as obtained from the straight line relationship for small driving fields is $7 \cdot 3 \times 10^{4} \mathrm{~cm} / \mathrm{sec}$ oe, which is much larger than that measured both in $800 \AA$ and in $1600 \AA$ single nickel-iron films. It is interesting to note that in double films the wall mobility decreases for higher fields, just as is observed in single films ${ }^{4}$.

\begin{tabular}{rcccc} 
& \multicolumn{3}{c}{ Table 1} \\
$D(\AA)$ & $\begin{array}{c}\text { Single films } \\
m_{1}\left(10^{4} \mathrm{~cm} / \mathrm{sec} \text { oe }\right)\end{array}$ & $D(\AA)$ & $m_{1}\left(10^{4} \mathrm{~cm} / \mathrm{sec}\right.$ oe $)$ \\
$90^{1}$ & $1 \cdot 39$ & $2 \times 135^{8}$ & $9 \cdot 1$ \\
$260^{2}$ & $0 \cdot 91$ & $2 \times 210^{7}$ & $5 \cdot 4$ \\
$450^{3}$ & $0 \cdot 29$ & $2 \times 440^{8}$ & $4 \cdot 1$ \\
$880^{4}$ & $0 \cdot 71$ & $2 \times 870^{9}$ & $7 \cdot 3$ \\
$1,650^{5}$ & $0 \cdot 96$ & &
\end{tabular}

* Anisotropy field.

$\begin{array}{ccc} & \text { Table } 2 & \\ \text { Film } & H_{c}(\mathrm{oe}) & H_{k}{ }^{*}(\mathrm{oe}) \\ 1 & 1 \cdot 3 & 5 \cdot 0 \\ 2 & 1 \cdot 9 & 5 \cdot 0 \\ 3 & 1 \cdot 5 & 4 \cdot 2 \\ 4 & 3 \cdot 0 & 7 \cdot 0 \\ 5 & 1 \cdot 8 & 7 \cdot 4 \\ 6 & 0 \cdot 52 & 4 \cdot 8 \\ 7 & 0 \cdot 48 & 5 \cdot 0 \\ 8 & 0 \cdot 43 & 5 \cdot 4 \\ 9 & 0 \cdot 09 & 5 \cdot 4\end{array}$

In Table 1, wall mobilities measured in double and in single films are compared; Table 2 gives the $H_{c}$ and $H_{k}$ values of the films. That walls in double films move much faster than those in single films can easily be observed, which is clearly in contradiction to the results of Patton and Humphrey.

\section{S. Middelhoek}

D. WILD

IBM Zurich Research Laboratory, 8803 Rüschlikon-ZH,

Switzerland.

${ }^{1}$ Humphrey, F. B., and Clow, H., Nature, 204, 769 (1964).

${ }^{2}$ Clow, H., Nature, 194, 1035 (1962).

${ }^{3}$ Patton, C. E., and Humphrey, F. B., J. App. Phys., 37, 1270 (1966).

${ }^{4}$ Middelhoek, S., IBM J. Research Develop. (to be published). 